Canadian

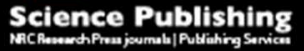

Canadian Journal of Civil Engineering Revue canadienne de génie civil

\title{
Long-Term Evaluation of the Operational Performance of Fixed Time Ramp Metering Control Strategy: A Freeway Corridor Study
}

\begin{tabular}{|r|l|}
\hline Journal: & Canadian Journal of Civil Engineering \\
\hline Manuscript ID & cjce-2014-0489.R1 \\
\hline Manuscript Type: & Article \\
\hline Date Submitted by the Author: & 18 -Feb-2015 \\
\hline Complete List of Authors: & $\begin{array}{l}\text { Osman, Osama; Louisiana State University, } \\
\text { Codjoe, Julius; Louisiana State University, } \\
\text { Ishak, Sherif; Louisiana State University, Civil and Environmental } \\
\text { Engineering } \\
\text { Rodriguez, Jose; Louisiana State University, } \\
\text { Russell, Marlene; Louisiana State University, }\end{array}$ \\
\hline Keyword: & $\begin{array}{l}\text { traffic control < Transportation, highways < Transportation, Ramp } \\
\text { metering, Active Traffic Management, Traffic Performance Measures }\end{array}$ \\
\hline & \multicolumn{2}{|l}{} \\
\hline
\end{tabular}

\section{SCHOLARONE}

Manuscripts 


\title{
Long-Term Evaluation of the Operational Performance of Fixed Time Ramp
}

Metering Control Strategy: A Freeway Corridor Study

\author{
Osama Osman, PhD Candidate \\ othabe1@1su.edu \\ Julius Codjoe, $\mathrm{PhD}$ \\ jcodjo1@1su.edu \\ Sherif Ishak ${ }^{1}, \mathrm{PhD}, \mathrm{PE}$ \\ sishak@1su.edu \\ Jose Rodriguez, Research Assistant \\ jrodr57@1su.edu \\ Marlene Russell, Research Assistant \\ mruss26@1su.edu \\ Department of Civil and Environmental Engineering \\ Louisiana State University, Baton Rouge, LA 70803 \\ Phone: (225) 578-4846
}

Number of Words: 5,325

Number of Tables: 8

Number of Figures: 4

${ }^{1}$ Corresponding Author 


\begin{abstract}
Ramp metering is one of the successful active traffic control strategies to control traffic flow at entry points to freeways. This study evaluates the effectiveness of fixed-time ramp metering control strategy on the day-to-day operation of traffic over two segments (easternmost and westernmost) of the I-12 corridor in Baton Rouge, Louisiana. Detector speeds and volumes were collected over 11 months and used to generate three performance measures, speed, travel time, and level of service to compare traffic conditions before and after the deployment of ramp meters. Comparative analysis, comprising statistical analysis, analysis of travel time savings, and level of service were then undertaken for traffic conditions before and after ramp meters installation. Overall, the results show some improvements in traffic conditions in the eastbound direction of the westernmost segment; however, the conditions slightly deteriorated on the westbound of the same segment. For the easternmost segment of I-12, no improvement was detected.
\end{abstract}

Keywords: Ramp Metering, Fixed Time, Active Traffic Management (ATM) 


\section{INTRODUCTION}

Urban freeways in major cities in the U.S. are operating near or beyond capacity conditions during peak periods due to increased travel demand. Such conditions often result in traffic breakdowns that lead to congestion which continues to escalate and spread over the surface transportation network in the U.S. The transportation community of practitioners, researchers, and public agencies now recognizes the need for better management of the existing network capacity as a viable alternative to capacity expansion projects. In recent years, more emphasis has been placed on Active Traffic Management (ATM) strategies such as speed harmonization, managed lanes, and ramp metering. Ramp metering is one of the successful active traffic control strategies that controls the flow of traffic entering the freeway facility from on-ramps in order to avoid breakdowns at merging areas and preserve the maximum traffic flow on the mainline.

Between June 2010 and November 2010, the Louisiana Department of Transportation and Development (LADOTD) deployed ramp metering control along a $24 \mathrm{~km}$ (15 mile) section of the I-12 in Baton Rouge, Louisiana. The main objectives were to reduce congestion, provide a safer merge operation at freeway entrances, improve travel time reliability of the corridor, and ultimately protect the investment. It was anticipated that all these objectives will be met if the mainline traffic speeds and flow rates were not significantly impacted by on-ramp merging traffic.

The objective of this study is to determine how effective the ramp metering control strategy was in alleviating congestion on a segment of I-12. Detector speeds and volumes were used as performance measures and were collected along a study segment of I-12 and then converted into 
equivalent travel time savings. The study recognizes the effect of using an appropriate assessment period as well as considering the effect of evolving traffic patterns on travel speeds within the corridor. After ramp meters were installed, a total of 11 months' worth of data was collected and analysed to compare traffic conditions before and after the deployment of ramp meters.

\section{BACKGROUND}

Several studies have been conducted to evaluate the overall benefits of ramp metering in terms of throughput, travel speeds and travel times on the mainline. For instance, Bhouri and Kaupplia (2011) evaluated the travel time reliability benefits of ramp metering. The study applied four different categories of performance measures to assess the travel time reliability benefits: statistical range methods, buffer time methods, tardy trip measures, and probabilistic measures. The study concluded that the different reliability measuring methods lead to inconsistency of results, and that in order to reach the optimal policy solutions, the benefits from improvement of average travel time and travel time reliability need to be separated.

Levinson and Zhang (2006) analysed the results of a test conducted on the ramp meters in the Twin Cities that involved turning the meters off for eight weeks. The authors used seven different performance measures to assess the effectiveness of the ramp meters: mobility, equity, productivity, consumers' surplus, accessibility, travel time variation, and travel demand responses were compared for the cases of with and without the ramp meters. Despite the analysis results show the effectiveness of ramp meters in reducing travel time variation, the study concluded that ramp metering was more helpful for long trips than short trips. 
Ramp meters proved ability to reduce the risk of merging accidents by reducing the possible conflicts at the merging areas on highways and freeways as shown in three different studies by Washington State Department of Transportation (WSDOT) (2012), Georgia Department of Transportation (2010), and the California Department of Transportation (2000). Similar safety observations have been made by Lee et al. (2005) who concluded that the local ALINEA ramp metering control could reduce 5\%-37\% crash potential estimated by the real time prediction crash model. Another practical case showing evidence of the merits of ramp metering is that of the Twin cities in Minnesota which had 430 active ramp meters turned off during the fall of 2000 due to the public questioning its effectiveness. The results were a decline in through traffic by $14 \%$, a doubling of travel time unpredictability, and a $26 \%$ increase in crash rate which was the equivalent of 1,041 crashes per year (Twin Cities Ramp Meter Evaluation: Final Report, 2001). In this study the results showed also that travel speeds on the freeway mainline improved with ramp metering by an average of $14 \%$ or $12 \mathrm{~km} / \mathrm{h}$. Likewise, a study that was jointly undertaken by the Kansas Department of Transportation and Missouri Department of Transportation that studied the effectiveness of ramp meters on I-435 based on the accident reduction, speed and travel times, compliance, ramp delay, traffic incident management, and feedback from the general public, local officials, and law enforcement. The study showed that ramp metering is beneficial through significantly reducing the number of accidents by $64 \%$, cutting accidents due to merging by $81 \%$, making merging maneuvers easier to conduct, keeping speeds and travel times at reliable levels (Ramp Metering, 2001 Evaluation Report: Maximizing the Flow, 2001).

$\mathrm{Wu}$ et al. (2007) investigated the impacts of ramp metering on driver behaviours in South England. The research studied the performance of drivers on ramps and on motorway 
carriageways with and without ramp metering. The main measures used in the study are: speed, headway, acceleration and deceleration, accepted gap size, merge distance, and speed at merge. The study showed that ramp metering resulted in changing driving behaviour on the motorway carriageway and on the ramp. More so, the study showed an improvement in the merging condition of the on-ramp traffic, while a speed reduction was noticed for the motorway carriageway traffic.

WSDOT (2000) evaluated its Renton Ramp Meters at nine locations on the I-405 in terms of travel times and speeds. The results showed that ramp meters effectively increased speeds by 11 to $32 \mathrm{~km} / \mathrm{h}$, and provided travel time savings of 3 to 16 minutes, depending on the time of day.

Zhang and Levinson (2010) studied the traffic flow characteristics at twenty seven active bottlenecks in the Twin Cities using flow and occupancy data obtained from 4000 single loop detectors. The results of study showed that ramp metering could increase capacity by postponing or eliminating bottleneck activation, accommodating higher flows during the pre-queue transition period than no-control and increasing queue discharge flow rates after breakdown.

$\mathrm{Xu}$ et al. (2013) proposed a local ramp metering algorithm based on Takagi-Sugeno type fuzzy logic control (FLC). The authors used the weighted total time spent (WTTS) by vehicles on the freeway mainline and the on-ramp to study the effectiveness of the proposed algorithm. Simulation results using PARAMICS showed the potential of the proposed algorithm to achieve balance between traffic conditions on the mainline and on the on-ramp. 
This section presented a brief review of a few ramp metering studies for performance evaluation of algorithms and for system wide evaluation of benefits. None of the studies considered the effect of growth in traffic demand over time. Therefore, this study attempts to capture the combined effects of both traffic growth over time and the ramp metering.

\section{STUDY AREA}

A total of 16 ramp meters were installed in 2010 along the $24 \mathrm{~km}$ (15 mile) corridor of I-12 in Baton Rouge, Louisiana. Since this was the first time ramp metering control was adopted in the state of Louisiana, a simple pre-timed operation with a fixed cycle length was used. During weekdays, the meters are turned on during the AM peak period (6:00 a.m. - 9:00 a.m.) for westbound traffic, and during the PM peak period (3:00 p.m. - 7:00 p.m.) for eastbound traffic. For these time periods, the signals operate on a cycle of 2 seconds green and 2 seconds red. If there are no vehicles on the ramps, the signals turn red for any coming vehicle to stop before merging with the mainline traffic. MIST (Management Information System for Transportation) and DCMS (Data Collection and Management Service) detectors, installed along two short segments of the corridor, collect traffic speed and volume data on the freeway and these were used as performance measures for the study. The MIST segment is $3 \mathrm{~km}$ (1.85 miles) long and in the westernmost part of the corridor, while the DCMS segment is $5 \mathrm{~km}(3.17$ miles $)$ long on the easternmost part. The two segments are $11 \mathrm{~km}(7 \mathrm{miles})$ apart. FIGURE 1 shows the approximate locations of ramp meters, MIST, and DCMS detectors. MIST detectors 60001, 60003, 60005, 60007, and 60009 as well as DCMS detectors 10001 and 10003 collect data for westbound traffic during the AM peak, and MIST detectors 60002, 60004, 60006, 60008, and 60010 as well as DCMS detectors 10002 and 10004 collect data for eastbound traffic during the PM peak. 


\section{DATA COLLECTION}

Traffic data (speeds and volumes) were collected for the time period the ramp meters were active, during the AM peak period (6:00 a.m. - 9:00 a.m.) for westbound traffic, and during the PM peak period (3:00 p.m. - 7:00 p.m.) for eastbound traffic. Data for the first month of activation of each ramp meter was discarded as drivers were still in the process of getting familiarized with the new traffic control, and therefore, their behaviour may deviate from the norm.

For the MIST segment, the detectors continuously measure traffic data at 30 -second intervals for each lane. The data was then aggregated into 15 minute intervals and speeds were averaged and volumes were added for all vehicles within each 15 minute period. For westbound traffic, MIST detectors \#60001, \#60003, \#60005, \#60007, and \#60009 recorded data for the before- period $(06 / 01 / 06-05 / 31 / 10)$ and after- period $(07 / 01 / 10$ - 05/31/11). For eastbound traffic, MIST detectors \#60002, \#60004, \#60006, \#60008, and \#60010 recorded data for the before- period $(12 / 01 / 06-11 / 30 / 10)$ and for the after- period $(01 / 01 / 11-11 / 30 / 11)$.

For the DCMS segment, traffic data were continuously measured for all lanes and aggregated into 5 minute intervals for all vehicles. For westbound traffic, DCMS detectors \#10001 and \#10003 recorded data for a different before- period (08/21/09 - 05/31/10) than that of the MIST segment because of unavailability of data for the entire period. However, the detectors collected data for the same after- period $(07 / 01 / 10-05 / 31 / 11)$. For the eastbound traffic, DCMS \#10002 and \#10004 recorded data for the before- period (08/21/09 - 11/30/10) and for the after- period $(01 / 01 / 11-05 / 31 / 11)$ 
Speeds averaging $129 \mathrm{~km} / \mathrm{h}$ or higher were discarded as outliers since such values were highly unlikely to be sustained for 5 minutes or 15 minutes during peak periods, and therefore, denote a detector malfunction. The collected data for the before- and after- periods were done over various weather and incident conditions. This means that this evaluation study accounts for general conditions including recurrent and non-recurrent conditions. It should be also noted that during the course of the study, a $14.4 \mathrm{~km}$ (9 miles) portion of the DCMS segment was undergoing major construction, specifically between the O'Neal Lane interchange and Walker/La. 447 interchange. This was started in early 2009 and lasted through the data collection period following the ramp meter installation.

\section{METHODOLOGY}

The mainline speeds recorded at 14 detector locations within the study area were evaluated to establish a baseline for comparison between traffic conditions before and after the ramp metering implementation. For abbreviation, the "after" and "before" ramp metering periods will be referred to as condition A and B, respectively. Data for the first month was discarded from the analysis to allow for familiarizing drivers of the ramp meters. Different types of analysis were conducted to measure the effectiveness of the ramp metering using the aforementioned collected data because of the different durations of data collection for the two detector types. Speed trends were constructed to capture the effect of traffic growth if any, comparative analyses of speeds, travel times, and level of service were also conducted to measure the effect of ramp meters on speed variation along the corridor. 


\section{TRENDS OF TRAFFIC SPEED AND DEMAND CONDITIONS}

Given the inherent variation in traffic conditions on weekdays, the analysis was conducted for each weekday independently. For MIST detectors, the speed was averaged at each detector location over the four lanes in each direction to obtain a single speed value for each 15 minute period for each weekday in the four year period for condition B. These were then grouped by weekday. For instance, a typical weekday would have approximately 208 speed averages (52 weeks x 4 years) for every 15 minute period. For DCMS detectors, average speed data were collected in the field; therefore, there was no need to average the collected speed data.

In order to capture the effect of growth in travel demand on traffic conditions, the MIST segment was analysed to identify any trends. Since traffic growth in any area should be consistent, any results could be applied for the DCMS segment as well. The trends of traffic speed were constructed for each weekday and each 15 minute time interval. For illustration, FIGURE 2 shows the speed trend for four different 15 -minute periods on Wednesdays over the four year period preceding ramp metering activation. It shows that the westbound AM peak periods predominantly exhibited free-flow conditions, while the eastbound PM peak periods exhibited mixed clusters of free-flow and congested traffic conditions. Similar distributions were obtained for all other intervals for each weekday.

Linear models were fitted to the speed data to determine if a changing trend exists because of traffic growth. Low $R^{2}$ values were obtained in most cases, which suggest that the effect of traffic growth on traffic speed was not significant over the four year period. Since no significant speed trend could be observed over time, all observations within the four year period were not 
considered time dependent, and therefore, the variation for each 15-minute period could be considered purely random. The statistical comparisons therefore considered all observations within the same 15 minute period during condition B as representative of the same population.

In analysing the traffic demand at each segment, it was obvious that the hourly demand for MIST segment slightly increased on the Eastbound from condition B to condition C, whereas, it significantly increased for the Westbound on that segment, as shown in TABLE 1. On the other hand, for DCMS segment, the hourly demand either remained unchanged or slightly decreased from condition B to A in both directions, as shown in TABLE 2.

\section{COMPARATIVE ANALYSIS}

Because of the different periods of data collection of the two types of detectors, two different statistical approaches were used to analyse the two segments.

\section{MIST Segment}

Using the observations for each weekday in the four-year period of condition $\mathrm{B}$, the $90 \%$ confidence bounds for speeds were estimated for each 15 minute interval using SAS. This procedure produced the mean, lower limit and upper limit of speeds for each weekday and each 15 minute interval. FIGURE 3 shows the corresponding mean, lower limit, and upper limit of $103.6,102$, and $105.6 \mathrm{~km} / \mathrm{h}$ respectively.

Statistical analyses were conducted at a $90 \%$ confidence level to determine if conditions A and B were significantly different in terms of traffic speed within the merging area. Significant differences are detected when the observed speed for a particular 15 minute period on a weekday 
in condition A falls outside the confidence limits for the speed distribution determined from condition B. Significant differences can also be identified as significant increases or decreases in speed, depending on whether they fall above the upper limit or below the lower limit of the confidence bounds, as shown in FIGURE 3.

Since weekdays were analysed independently, the statistical comparison was made for each 15 minute interval of the peak period (PM period for eastbound and AM period for westbound). TABLE 3 shows the results of the statistical tests for each time interval on Mondays (eastbound). For each time interval, the percentage of time periods is shown for the three possible cases: (1) significant increase, (2) insignificant difference, and (3) significant decrease. For instance, 13\% of Mondays show a significant decrease in speed, $15 \%$ an insignificant change of speed, and $71 \%$ a significant increase in speed, during the 17:00-17:15 time interval. This implies that ramp metering was effective $71 \%$ of the time on Mondays during this particular time period.

The table also shows the average speed difference and its percentage of the average speed for each of the three cases. For the same time interval (17:00-17:15), cases with a significant decrease in speed showed an average reduction of $39 \mathrm{~km} / \mathrm{h}$, while cases with a significant increase in speed showed an average increase of $15 \mathrm{~km} / \mathrm{h}$. The results for all time periods combined are also shown in the table and indicate that ramp metering was effective $51 \%$ of all time periods on Mondays with an average increase of $11 \mathrm{~km} / \mathrm{h}$. The remaining $49 \%$ comprise of cases with no significant difference or a significant decrease in speed.

The results for all time intervals combined are shown in TABLE 4 by weekday and direction. Time periods with a significant increase in speed ranged from $42 \%$ to $52 \%$ and from $34 \%$ to 
$46 \%$ for the eastbound PM and westbound AM peak periods, respectively. This corresponded to an increase in speed ranging from 11 to $13 \mathrm{~km} / \mathrm{h}$ (eastbound PM peak) and from 1.6 to $11 \mathrm{~km} / \mathrm{h}$ (westbound AM peak). The significant increase in speed may be attributed to the ramp metering control. The results, however, show no significant differences in speed in $41 \%$ and $28 \%$ of the time periods for eastbound PM and westbound AM peak periods. Also, $12 \%$ and $29 \%$ of the time periods exhibited a significant decrease in speed for the eastbound PM and westbound AM peak periods. Such cases suggest worse traffic conditions with ramp metering control and may be attributed to unusually heavy congestion resulting from downstream incidents, which could not have been prevented with ramp metering control.

\section{DCMS Segment}

For DCMS segment, two samples t-test at $90 \%$ confidence bounds was conducted for each detector, each weekday, and each 5 minutes interval using SAS. This procedure produced the differences in mean speeds between Conditions B and A, p-value for testing the equality of variances between $\mathrm{B}$ and $\mathrm{A}$, and two p-values for the t-test: one for equal variances (Pooled ttest) and another for unequal variances (Satterthwaite t-test).

Since weekdays were analysed independently, the statistical comparison was made for each 5 minute interval of the peak period (PM period for eastbound and AM period for westbound). The results for all time intervals combined are shown in TABLE 5 by weekday and direction. For the eastbound PM, it is clear that there is always a significant decrease in speed ranging from 4.6 to $7.15 \mathrm{~km} / \mathrm{h}$, whereas for the westbound there is a significant decrease in speed ranging from 5.84 to $14.13 \mathrm{~km} / \mathrm{h}$, except for Thursday where there was no significant change in speed. 


\section{TRAVEL TIME SAVINGS}

Equation (1) was applied to estimate the average travel time saving per kilometre per day $\operatorname{TTS}(j, k)$ for weekday $j$ and outcome $k$ :

$$
\operatorname{TTS}(j, k)=\frac{1}{N(i, j, k)} \sum_{i, n}^{N}\left(\frac{1}{V_{B}(i, j)}-\frac{1}{V_{\mathrm{A}}(i, j, k, n)}\right) * q_{A}(i, j, k, n)
$$

Where $V_{A}(i, j, k, n)$ is the average speed of the two detectors for condition A, 15-min interval $i$, weekday $j$, outcome $k$, and day number $n, V_{B}(i, j)$ is the average speed of the two detectors for all days of condition $\mathrm{B}, 15$-min interval $i$, weekday $j, q_{A}(i, j, k, n)$ is the total traffic volume observed for condition A, time interval $i$, weekday $j$, outcome $k$, and day number $n$, and $N(i, j, k)$ is the total number of days data is available for interval $i$, weekday $j$, and outcome $k$.

\section{MIST Segment}

The total travel time saving was estimated for each weekday from time intervals before and after ramp metering was introduced. This was estimated separately for each of the three possible statistical outcomes in TABLE 3: (1) a significant decrease, (2) no significant difference, and (3) a significant increase in speed. For the westbound AM peak period, the normalized travel time savings were estimated from detectors 60001, 60003, 60005, 60007 and 60009 and averaged for each weekday to represent total travel time savings in vehicle hours per mile per day. For the eastbound PM peak period, detectors 60002, 60004, 60006, 60008 and 60010 were used to estimate the travel time savings.

FIGURE 4 shows the total travel time savings per mile per day for each weekday and each statistical outcome. For the eastbound PM peak period, the largest travel time saving for 
intervals with a significant increase in speed was observed on Wednesdays and amounted to about 20 vehicle hours per mile.

For all other weekdays, the savings ranged from 8 to 13 vehicle hours per mile. On the other hand, intervals with a significant decrease in speed exhibited an overall increase in travel times from 34 to 99 vehicle hours per mile. Such intervals may reflect conditions of heavy congestion during which ramp metering was not effective. For the westbound AM peak period, much less travel time savings, around 8 vehicle hours per mile, were achieved for intervals with significant increase in speed for Tuesdays and Wednesdays and $4-6$ vehicle hours per mile for the rest of the weekdays. This is intuitive since traffic operates near free-flow conditions during the AM peak period, and therefore, differences in travel times are expected to be minor. For both the AM and PM peak periods, intervals with no significant change exhibited positive travel time savings, around 1 vehicle hour per mile, but were considered statistically insignificant.

\section{DCMS Segment}

TABLE 6 shows the total travel time savings per mile per hour for the DCMS segment for each weekday and each statistical outcome. For all weekdays of the eastbound PM peak period, the travel time loss ranges from 1.81 to 3.08 vehicle hour per mile.

On the other hand, the westbound AM peak period shows a saving in travel time of 0.93 vehicle hour per mile on Thursdays; however, the travel time loss ranges from 4.47 to 12.97 vehicle hour per mile for the other days of the week. This may reflect conditions of heavy congestion during which ramp metering was not effective for both the eastbound and westbound directions. 


\section{LEVEL OF SERVICE}

The level of service distribution was then computed and compared for the before- (Condition B) and after- (Condition A) periods of the ramp metering deployment using the procedures in the Highway Capacity Manual for basic freeway segment. The analysis was developed utilizing the volume data collected in this study. The level of service criteria is given in terms of the percentage volume distribution of vehicles during an analysis period of 15 minutes (MIST data) and 5 minutes (DCMS data).

\section{MIST Segment}

TABLE 7 shows level of service (LOS) results for the time period 08:15 to 08:30 for all weekdays on the westbound (AM peak). Generally, higher LOS distribution in the after period for LOS A and LOS B indicate an improvement, while higher LOS distribution in the after period for the remaining LOS indicate a deterioration in traffic conditions.

The results for Mondays show that for detectors 60001 and 60005 before the ramp metering there was approximately $20 \%$ to $26 \%$ of the traffic component experiencing a Category A LOS which reduced to approximately $5 \%$ and $0 \%$ in the after study period. Overall both detectors had a worsened LOS with more drivers experiencing Level of Service C compared to the before period. Similarly, for detector 60003 , it is clear that there is a little deterioration in traffic conditions with increased percent of LOS C. The comparison between the before and after periods shows very little change for detector 60007. However there is evidence of a slight improvement in Level A and Level B LOS. Finally, for detector 60009, again little evidence of a notable change that occurred between the before and after periods but there was however a decrease in the LOS particularly from Level A to Level B. 
The results for the other weekdays indicate that there was quite a reduction in percentage of LOS A at detectors 60001, 60005, and 60007. Both detectors 60001 and 60005 had a slightly greater deterioration with more drivers experiencing LOS C compared to the before period. The recordings at detector 60007 showed a slight increase in percentage of LOS A and an improvement in LOS C, with it being less populated in the after period. Finally, detectors 60003 and 60009 show a drop in the after period for LOS A and very small increase at LOS B. It appears, therefore, that the ramp metering has not improved traffic flow conditions at this particular time interval.

\section{DCMS Segment}

In looking at the DCMS segment, the Level of Service results for the time period, 08:15 to 08:20 am, are shown in TABLE 8 for the westbound (AM peak) traffic, for all weekdays. The results for Mondays show that for detector 10001, the percentage of LOS A has been improved from $68.3 \%$ to $76.6 \%$, and percentage of LOS $\mathrm{F}$ has been decreased from $31.7 \%$ to $23.4 \%$. For detector 10003, there is little improvement at the LOS A being $4.9 \%$ before and $6.5 \%$ after. However, there is a notable increase at the LOS F from around $61 \%$ to $74 \%$. This indicates that at detector 10003 , the traffic conditions for the after period is worse than the before period on Monday.

In looking at the other weekdays, the results show that there is an improvement on Thursday at detector 10001. However, for all other weekdays at detector 10001 and all weekdays at detector 10003, results show that despite there is a little increase for LOS A on some weekdays there is a significant increase in the percentage of tie having LOS F. This indicates that ramp meters were not effective at the easternmost road segment and the conditions are worse for the after period. 


\section{SUMMARY AND CONCLUSIONS}

This study examined the effectiveness of ramp metering, as an active traffic management strategy, in alleviating traffic congestion on a section of I-12 in Baton Rouge, Louisiana. The assessment was made for the time period when the ramp meters were active from 3:00 to 7:00 $\mathrm{pm}$ in the eastbound direction, and from 6:00 to 9:00 am in the westbound direction. Two segments of I-12 were selected, the westernmost segment is 1.85 miles long and the easternmost segment is 3.17 miles long. The two segments are 7 miles apart. Three performance measures were selected for the study: speed, travel time, and level of service.

For the westernmost segment, the statistical results of the comparative speed analysis before and after ramp meters installation revealed a significant increase in average speed of nearly $11 \mathrm{~km} / \mathrm{h}$ $47 \%$ of the time, and a significant speed decrease of $27 \mathrm{~km} / \mathrm{h} 12 \%$ of the time for the eastbound PM peak period. For the westbound AM peak period, the results show a significant increase in speed of nearly $8 \mathrm{~km} / \mathrm{h} 43 \%$ of the time and a significant decrease in speed of nearly $11 \mathrm{~km} / \mathrm{h}$ $29 \%$ of the time. On the contrary, the statistical results for the easternmost segment revealed deterioration in traffic conditions for both the morning and evening peak periods. Considering all time intervals combined, there was an average decrease in speed from 99.63 to $93.94 \mathrm{~km} / \mathrm{h}$ for the eastbound PM and 86.55 to $78.95 \mathrm{~km} / \mathrm{h}$ for the westbound AM peak periods.

Travel time savings over the westernmost segment, after the implementation of ramp metering and normalized by traffic volume for each weekday, also showed an average travel time saving of 7 vehicle hours per $\mathrm{km}$ for the PM peak period and 4 vehicle hours per km for the AM peak period. On the other hand, intervals with significant decrease in speed exhibited an increase in 
average travel times of 39 and 16 vehicle hours per $\mathrm{km}$, for the PM and AM peak periods, respectively. For the easternmost segment, the average travel times also increased for both peak periods. The results were consistent with the level of service analysis which showed an overall deterioration of traffic conditions during both peak periods for the westernmost segment and deteriorated LOS distributions for both peak periods for the easternmost segment. For the eastbound PM peak period, the percentage of time having LOS A has been decreased, and the time percentage of time having LOS F has been significantly increased for the different time intervals for PM and AM intervals.

Overall, the assessments for the westernmost segment showed some improvements in traffic conditions with the implementation of ramp metering during the more congested eastbound PM peak period. On the other hand, no improvement was observed on the easternmost segment. In fact, traffic conditions appeared to have worsened on the easternmost segment after ramp metering implementation. This can be attributed to the concurrent construction work that was taking place on that segment after the ramp meters installation, which led to operating the easternmost segment with less number of lanes for the same demand.

\section{ACKNOWLEDGEMENTS}

This project was funded by Louisiana Transportation Research Centre. The contents of this paper reflect the views of the authors, who are solely responsible for the facts and the accuracy of the material and information presented herein. 


\section{REFERENCES}

Becerril-Arreola, R. and Aghdam, A.G. 2007. Decentralised Nonlinear Control with Disturbance Rejection for On-Ramp Metering in Highway. IET Control Theory \& Application, 1, no. 1: 253-262.

Bhouri, N., and Kaupplia, J. 2011. Managing Highways for Better Reliability -Assessing Reliability Benefits of Ramp Metering. Journal of the Transportation Research Record, 2229, no. 1: 1-7.

Evaluation of Renton Ramp Meters on I-405, 2000. Washington State Department of Transportation, Washington State.

Lee, C., Hellienga, B. and Ozbay, K. 2005. Quantifying Effects of Ramp Metering on Freeway Safety. Accident Analysis and Prevention, 38, no. 2, 279-288.

Levinson, D., and Zhang, L. 2006. Ramp meters on trial: Evidence from the twin cities metering holiday. Transportation Research Part A: Policy and Practice, 40, no. 10: 810-828.

Ramp Meter Design Manual, 2000. California Department of Transportation, Traffic Operations Program, CA.

Ramp Metering, 2011 Evaluation Report: Maximizing the Flow. The Kansas and Missouri Departments of Transportation, Kansas and Missouri.

Ramp Meters. Georgia Department of Transportation. Available from http://www.dot.ga.gov/travelingingeorgia/rampmeters/Pages/default.aspx. [Accessed 25 May 2012].Trinh, H., and Gibbens , J. 2000. Evaluation of Renton Ramp Meters on I405. Washington State Department of Transportation, Northwest Region Traffic Systems Management Centre, Washington. 
Twin Cities Ramp Meter Evaluation: Final Report. Minnesota Department of Transportation. Cambridge Systematics, Inc., Minnesota.

Wu J., McDonald , M. and Chatterjee, K. 2007. A detailed evaluation of ramp metering impacts on driver behaviour. Transportation Research Part F, 10: 61-75.

Xu, J., Zhao, X. and Srinivasan, D. 2013. On Optimal Freeway Local Ramp Metering Using Fuzzy Logic Control with Particle Swarm Optimisation. IET Intelligent Transportation Systems, 7, no. 1: 95-104.

Zhang, L., and Levinson, D. 2010. Ramp metering and the capacity of active freeway bottlenecks. Transportation Research Part A, 44, no. 4: 218-235. 
TABLE 1 Hourly Traffic Demands for MIST Segment

\begin{tabular}{|l|c|c|c|c|}
\cline { 2 - 5 } \multicolumn{1}{c|}{} & \multicolumn{2}{c|}{ EastBound MIST 60006 } & \multicolumn{2}{c|}{ WestBound MIST 60005 } \\
\cline { 2 - 5 } \multicolumn{1}{c|}{} & $\begin{array}{c}\text { Volume Before } \\
(\text { Veh/hr) }(\mathrm{B})\end{array}$ & $\begin{array}{c}\text { Volume After } \\
(\mathrm{Km} / \mathrm{h})(\mathrm{A})\end{array}$ & $\begin{array}{c}\text { Volume Before } \\
(\text { Veh/hr })(\mathrm{B})\end{array}$ & $\begin{array}{c}\text { Volume After } \\
(\mathrm{Km} / \mathrm{h})(\mathrm{A})\end{array}$ \\
\hline Mondays & 4637 & 4824 & 5606 & 6793 \\
\hline Tuesdays & 4666 & 4914 & 5826 & 6913 \\
\hline Wednesdays & 4683 & 4721 & 5727 & 7127 \\
\hline Thursdays & 4570 & 4797 & 5479 & 7106 \\
\hline Fridays & 4309 & 4374 & 5179 & 6452 \\
\hline
\end{tabular}


TABLE 2 Hourly Traffic Demands for DCMS Segment

\begin{tabular}{|l|c|c|c|c|}
\cline { 2 - 5 } \multicolumn{1}{c|}{} & \multicolumn{2}{c|}{ EastBound DCMS 10002 } & \multicolumn{2}{c|}{ WestBound DCMS 10001 } \\
\cline { 2 - 5 } \multicolumn{1}{c|}{} & $\begin{array}{c}\text { Volume Before } \\
\text { (Veh/hr) }(\mathrm{B})\end{array}$ & $\begin{array}{c}\text { Volume After } \\
(\mathrm{Km} / \mathrm{h})(\mathrm{A})\end{array}$ & $\begin{array}{c}\text { Volume Before } \\
\text { (Veh/hr) }(\mathrm{B})\end{array}$ & $\begin{array}{c}\text { Volume After } \\
(\mathrm{Km} / \mathrm{h})(\mathrm{A})\end{array}$ \\
\hline Mondays & 2492 & 2321 & 3587 & 3346 \\
\hline Tuesdays & 2454 & 2440 & 3676 & 3478 \\
\hline Wednesdays & 2551 & 2455 & 3714 & 3560 \\
\hline Thursdays & 2501 & 2478 & 3151 & 3487 \\
\hline Fridays & 2553 & 2464 & 3575 & 3376 \\
\hline
\end{tabular}


TABLE 3 Statistical Results for Speed on Mondays (Eastbound PM Peak) for MIST segment

\begin{tabular}{|c|c|c|c|c|c|c|}
\hline \multirow{2}{*}{$\begin{array}{c}\text { EB } \\
\text { (PM Peak) } \\
\text { Time Interval }\end{array}$} & \multicolumn{3}{|c|}{$\%$ of Time Periods } & \multicolumn{3}{|c|}{$\begin{array}{c}\text { Difference in Speed }(\mathrm{km} / \mathrm{h}) \\
(\% \text { Difference })\end{array}$} \\
\hline & $\begin{array}{l}\text { Significant } \\
\text { Decrease }\end{array}$ & $\begin{array}{c}\text { Insignificant } \\
\text { Change }\end{array}$ & $\begin{array}{l}\text { Significant } \\
\text { Increase }\end{array}$ & $\begin{array}{l}\text { Significant } \\
\text { Decrease }\end{array}$ & $\begin{array}{l}\text { Insignificant } \\
\text { Change }\end{array}$ & $\begin{array}{c}\text { Significant } \\
\text { Increase }\end{array}$ \\
\hline $15: 00-15: 15$ & $29 \%$ & $30 \%$ & $39 \%$ & $-3.2(-4 \%)$ & $0.0(0 \%)$ & $12.9(8 \%)$ \\
\hline $15: 15-15: 30$ & $32 \%$ & $28 \%$ & $40 \%$ & $-3.2(-4 \%)$ & $0.0(0 \%)$ & $12.9(9 \%)$ \\
\hline $15: 30-15: 45$ & $24 \%$ & $34 \%$ & $40 \%$ & $-6.4(-7 \%)$ & $0.0(0 \%)$ & $6.4(7 \%)$ \\
\hline $15: 45-16: 00$ & $24 \%$ & $40 \%$ & $36 \%$ & $-6.4(-6 \%)$ & $0.0(0 \%)$ & $12.9(9 \%)$ \\
\hline $16: 00-16: 15$ & $12 \%$ & $49 \%$ & $39 \%$ & $-12.9(-8 \%)$ & $0.0(0 \%)$ & $12.9(8 \%)$ \\
\hline $16: 15-16: 30$ & $6 \%$ & $55 \%$ & $39 \%$ & $-19.3(-20 \%)$ & $1.6(2 \%)$ & $9.7(10 \%)$ \\
\hline $16: 30-16: 45$ & $6 \%$ & $33 \%$ & $60 \%$ & $-35.4(-41 \%)$ & $3.2(3 \%)$ & $9.7(12 \%)$ \\
\hline $16: 45-17: 00$ & $8 \%$ & $29 \%$ & $62 \%$ & $-41.8(-50 \%)$ & $3.2(3 \%)$ & $11.3(14 \%)$ \\
\hline $17: 00-17: 15$ & $13 \%$ & $15 \%$ & $71 \%$ & $-38.6(-49 \%)$ & $3.2(3 \%)$ & $14.5(18 \%)$ \\
\hline $17: 15-17: 30$ & $12 \%$ & $10 \%$ & $78 \%$ & $-41.8(-54 \%)$ & $4.8(6 \%)$ & $14.5(19 \%)$ \\
\hline $17: 30-17: 45$ & $7 \%$ & $10 \%$ & $82 \%$ & $-38.6(-48 \%)$ & $4.8(6 \%)$ & $12.9(16 \%)$ \\
\hline $17: 45-18: 00$ & $5 \%$ & $23 \%$ & $72 \%$ & $-30.6(-37 \%)$ & $4.8(5 \%)$ & $12.9(14 \%)$ \\
\hline $18: 00-18: 15$ & $2 \%$ & $53 \%$ & $44 \%$ & $-19.3(-21 \%)$ & $3.2(4 \%)$ & $11.3(13 \%)$ \\
\hline $18: 15-18: 30$ & $2 \%$ & $51 \%$ & $47 \%$ & $-6.4(-7 \%)$ & $1.6(2 \%)$ & $11.3(12 \%)$ \\
\hline $18: 30-18: 45$ & $4 \%$ & $61 \%$ & $34 \%$ & $-6.4(-7 \%)$ & $0.0(0 \%)$ & $11.3(12 \%)$ \\
\hline $18: 45-19: 00$ & $15 \%$ & $48 \%$ & $36 \%$ & $-3.2(-4 \%)$ & $0.0(-1 \%)$ & $9.7(10 \%)$ \\
\hline Total Interval & $13 \%$ & $36 \%$ & $51 \%$ & $-19.3(-23 \%)$ & $1.6(2 \%)$ & $11.3(12 \%)$ \\
\hline
\end{tabular}


Osman, O., J. Codjoe, S. Ishak, J. Rodriguez, and M. Russell

TABLE 4 Results for All Time Intervals Combined by Weekday and Direction for MIST Segment

\begin{tabular}{|c|c|c|c|c|c|c|c|}
\hline & & \multicolumn{3}{|c|}{$\%$ of Time Periods } & \multicolumn{3}{|c|}{$\begin{array}{c}\text { Difference in Travel Speed }(\mathrm{km} / \mathrm{h}) \\
(\% \text { difference) }\end{array}$} \\
\hline & & $\begin{array}{l}\text { Significant } \\
\text { Decrease }\end{array}$ & $\begin{array}{l}\text { Insignificant } \\
\text { Change }\end{array}$ & $\begin{array}{l}\text { Significant } \\
\text { Increase }\end{array}$ & $\begin{array}{l}\text { Significant } \\
\text { Decrease }\end{array}$ & $\begin{array}{l}\text { Insignificant } \\
\text { Change }\end{array}$ & $\begin{array}{l}\text { Significant } \\
\text { Increase }\end{array}$ \\
\hline \multirow{6}{*}{ 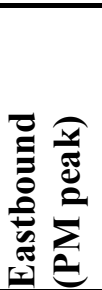 } & Mondays & $13 \%$ & $36 \%$ & $51 \%$ & $-19.3(-23 \%)$ & $1.6(2 \%)$ & $11.3(12 \%)$ \\
\hline & Tuesdays & $12 \%$ & $42 \%$ & $46 \%$ & $-21.0(-27 \%)$ & $1.6(3 \%)$ & $11.3(15 \%)$ \\
\hline & Wednesdays & $17 \%$ & $41 \%$ & $42 \%$ & $-32.2(-40 \%)$ & $1.6(2 \%)$ & $11.3(15 \%)$ \\
\hline & Thursdays & $11 \%$ & $45 \%$ & $44 \%$ & $-33.8(-42 \%)$ & $1.6(3 \%)$ & $11.3(13 \%)$ \\
\hline & Fridays & $8 \%$ & $40 \%$ & $52 \%$ & $-30.6(-38 \%)$ & $1.6(3 \%)$ & $13.0(16 \%)$ \\
\hline & Overall & $12 \%$ & $41 \%$ & $47 \%$ & $-27.4(-34 \%)$ & $1.6(3 \%)$ & $11.3(14 \%)$ \\
\hline \multirow{6}{*}{ 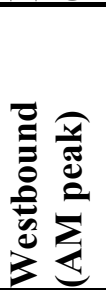 } & Mondays & $26 \%$ & $28 \%$ & $46 \%$ & $-11.3(-13 \%)$ & $0.0(1 \%)$ & $11.3(12 \%)$ \\
\hline & Tuesdays & $30 \%$ & $27 \%$ & $43 \%$ & $-16.0(-19 \%)$ & $0.0(1 \%)$ & $11.3(13 \%)$ \\
\hline & Wednesdays & $24 \%$ & $30 \%$ & $46 \%$ & $-16.0(-19 \%)$ & $0.0(1 \%)$ & $11.3(13 \%)$ \\
\hline & Thursdays & $25 \%$ & $31 \%$ & $44 \%$ & $-13.0(-14 \%)$ & $-3.2(-1 \%)$ & $1.6(7 \%)$ \\
\hline & Fridays & $39 \%$ & $27 \%$ & $34 \%$ & $-11.3(-11 \%)$ & $0.0(0 \%)$ & $9.7(11 \%)$ \\
\hline & Overall & $29 \%$ & $28 \%$ & $43 \%$ & $-11.3(-13 \%)$ & $0.0(0 \%)$ & $8.0(9 \%)$ \\
\hline
\end{tabular}


TABLE 5 Results for All Time Intervals Combined by Weekday and Direction for DCMS Segment

\begin{tabular}{|c|c|c|c|c|c|c|c|}
\hline & & $\begin{array}{c}\text { Speed } \\
\text { Before } \\
(\mathrm{km} / \mathrm{h}) \\
(\mathrm{B})\end{array}$ & $\begin{array}{c}\text { Speed } \\
\text { After } \\
(\mathrm{km} / \mathrm{h}) \\
(\mathrm{A})\end{array}$ & $\begin{array}{c}\text { Speed } \\
\text { Difference } \\
(\mathrm{km} / \mathrm{h}) \\
(\mathrm{B}-\mathrm{A})\end{array}$ & $\begin{array}{c}\text { Equality } \\
\text { of } \\
\text { Variances } \\
\text { (P-Value) }\end{array}$ & $\begin{array}{c}\text { Pooled } \\
\text { T-Test } \\
\text { (P-Value) }\end{array}$ & $\begin{array}{c}\text { Satterthwaite } \\
\text { T-Test } \\
\text { (P-Value) }\end{array}$ \\
\hline \multirow{6}{*}{ 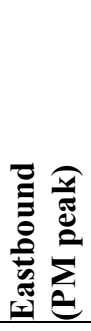 } & Mondays & 99.91 & 95.31 & 4.59 & 0.4482 & 0.0008 & 0.0008 \\
\hline & Tuesdays & 99.28 & 92.65 & 6.63 & 0.1691 & $<0.0001$ & $<0.0001$ \\
\hline & Wednesdays & 99.52 & 92.36 & 7.15 & 0.0753 & $<0.0001$ & $<0.0001$ \\
\hline & Thursdays & 99.84 & 94.45 & 5.39 & 0.3786 & 0.0003 & 0.0003 \\
\hline & Fridays & 99.59 & 94.93 & 4.63 & 0.8509 & 0.0014 & 0.0014 \\
\hline & Overall & 99.63 & 93.94 & 5.70 & 0.0817 & $<0.0001$ & $<0.0001$ \\
\hline \multirow{6}{*}{ 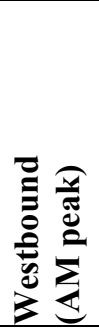 } & Mondays & 86.90 & 81.06 & 5.84 & 0.7097 & 0.0420 & 0.0420 \\
\hline & Tuesdays & 85.47 & 71.34 & 14.13 & 0.2024 & $<0.0001$ & $<0.0001$ \\
\hline & Wednesdays & 81.21 & 72.10 & 9.11 & 0.3689 & 0.0030 & 0.0030 \\
\hline & Thursdays & 77.67 & 78.68 & -1.00 & 0.2564 & 0.7470 & 0.7470 \\
\hline & Fridays & 101.47 & 91.64 & 9.85 & 0.5283 & 0.0072 & 0.0072 \\
\hline & Overall & 86.55 & 78.95 & 7.58 & 0.6574 & $<0.0001$ & $<0.0001$ \\
\hline
\end{tabular}


Osman, O., J. Codjoe, S. Ishak, J. Rodriguez, and M. Russell

TABLE 6 Travel Time Savings for All Time Intervals Combined by Weekday and Direction for DCMS Segment

\begin{tabular}{|c|c|c|c|c|c|c|}
\hline & & $\begin{array}{l}\text { Speed Before } \\
\qquad(\mathrm{km} / \mathrm{h}) \\
\text { (B) }\end{array}$ & $\begin{array}{l}\text { Speed After } \\
(\mathrm{km} / \mathrm{h}) \\
\text { (A) }\end{array}$ & $\begin{array}{c}\text { Speed } \\
\text { Difference } \\
(\mathrm{km} / \mathrm{h}) \\
(\mathrm{B}-\mathrm{A})\end{array}$ & $\begin{array}{l}\text { Traffic } \\
\text { Volume } \\
\text { (veh/hr) }\end{array}$ & $\begin{array}{c}\text { Travel Time } \\
\text { Saving (vehicle } \\
\text { hour } / \mathrm{km})\end{array}$ \\
\hline \multirow{5}{*}{ 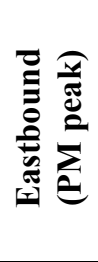 } & Mondays & 99.91 & 95.31 & 4.59 & 2321 & -1.12 \\
\hline & Tuesdays & 99.28 & 92.65 & 6.63 & 2440 & -1.76 \\
\hline & Wednesdays & 99.52 & 92.36 & 7.15 & 2455 & -1.91 \\
\hline & Thursdays & 99.84 & 94.45 & 5.39 & 2478 & -1.42 \\
\hline & Fridays & 99.59 & 94.93 & 4.63 & 2464 & -1.21 \\
\hline \multirow{5}{*}{ 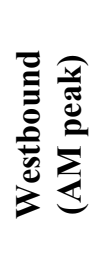 } & Mondays & 86.90 & 81.06 & 5.84 & 3346 & -2.78 \\
\hline & Tuesdays & 85.47 & 71.34 & 14.13 & 3478 & -8.06 \\
\hline & Wednesdays & 81.21 & 72.10 & 9.11 & 3560 & -5.54 \\
\hline & Thursdays & 77.67 & 78.68 & -1.00 & 3487 & 0.58 \\
\hline & Fridays & 101.47 & 91.64 & 9.85 & 3376 & -3.57 \\
\hline
\end{tabular}


Osman, O., J. Codjoe, S. Ishak, J. Rodriguez, and M. Russell

28

TABLE 7 Change in Level of Service Distribution Results for All Weekdays (Westbound AM Peak) [8:15-8:30] for MIST Segment

\begin{tabular}{|c|c|c|c|c|c|c|c|c|c|c|c|}
\hline \multirow{3}{*}{ Day } & \multicolumn{11}{|c|}{ LOS Distribution (\%) } \\
\hline & \multirow{2}{*}{$\begin{array}{c}\text { Detector } \\
\text { LOS } \\
\end{array}$} & \multicolumn{2}{|c|}{60001} & \multicolumn{2}{|c|}{60003} & \multicolumn{2}{|c|}{60005} & \multicolumn{2}{|c|}{60007} & \multicolumn{2}{|c|}{60009} \\
\hline & & Before & After & Before & After & Before & After & Before & After & Before & After \\
\hline \multirow{6}{*}{ Monday } & A & 25.71 & 5.13 & 46.51 & 43.59 & 18.54 & 5.00 & 3.94 & 4.65 & 14.29 & 6.52 \\
\hline & B & 16.43 & 20.51 & 44.96 & 56.41 & 29.80 & 10.00 & 70.87 & 88.37 & 51.43 & 71.74 \\
\hline & $\mathrm{C}$ & 57.86 & 74.36 & 8.53 & 0.00 & 49.67 & 85.00 & 25.20 & 6.98 & 34.29 & 21.74 \\
\hline & $\mathrm{D}$ & 0.00 & 0.00 & 0.00 & 0.00 & 1.99 & 0.00 & 0.00 & 0.00 & 0.00 & 0.00 \\
\hline & $\mathrm{E}$ & 0.00 & 0.00 & 0.00 & 0.00 & 0.00 & 0.00 & 0.00 & 0.00 & 0.00 & 0.00 \\
\hline & $\mathrm{F}$ & 0.00 & 0.00 & 0.00 & 0.00 & 0.00 & 0.00 & 0.00 & 0.00 & 0.00 & 0.00 \\
\hline \multirow{6}{*}{ Tuesday } & A & 19.42 & 0.00 & 29.01 & 28.21 & 15.65 & 0.00 & 0.76 & 2.27 & 7.46 & 4.26 \\
\hline & $\mathrm{B}$ & 9.35 & 10.26 & 57.25 & 71.79 & 25.17 & 9.52 & 57.25 & 56.82 & 42.54 & 51.06 \\
\hline & $\mathrm{C}$ & 71.22 & 89.74 & 13.74 & 0.00 & 49.66 & 90.48 & 41.98 & 40.91 & 50.00 & 44.68 \\
\hline & $\mathrm{D}$ & 0.00 & 0.00 & 0.00 & 0.00 & 9.52 & 0.00 & 0.00 & 0.00 & 0.00 & 0.00 \\
\hline & $\mathrm{E}$ & 0.00 & 0.00 & 0.00 & 0.00 & 0.00 & 0.00 & 0.00 & 0.00 & 0.00 & 0.00 \\
\hline & $\mathrm{F}$ & 0.00 & 0.00 & 0.00 & 0.00 & 0.00 & 0.00 & 0.00 & 0.00 & 0.00 & 0.00 \\
\hline \multirow{6}{*}{ Wednesday } & $\mathrm{A}$ & 20.57 & 0.00 & 32.31 & 26.32 & 16.44 & 0.00 & 1.52 & 0.00 & 7.09 & 0.00 \\
\hline & $\mathrm{B}$ & 12.77 & 13.16 & 55.38 & 73.68 & 23.97 & 10.00 & 60.61 & 78.57 & 46.46 & 65.22 \\
\hline & $\mathrm{C}$ & 66.67 & 86.84 & 12.31 & 0.00 & 55.48 & 85.00 & 37.88 & 21.43 & 46.46 & 34.78 \\
\hline & $\mathrm{D}$ & 0.00 & 0.00 & 0.00 & 0.00 & 4.11 & 5.00 & 0.00 & 0.00 & 0.00 & 0.00 \\
\hline & $\mathrm{E}$ & 0.00 & 0.00 & 0.00 & 0.00 & 0.00 & 0.00 & 0.00 & 0.00 & 0.00 & 0.00 \\
\hline & $\mathrm{F}$ & 0.00 & 0.00 & 0.00 & 0.00 & 0.00 & 0.00 & 0.00 & 0.00 & 0.00 & 0.00 \\
\hline \multirow{6}{*}{ Thursday } & A & 25.71 & 5.41 & 34.62 & 27.03 & 20.14 & 0.00 & 6.02 & 4.55 & 13.33 & 2.13 \\
\hline & $\mathrm{B}$ & 8.57 & 13.51 & 53.08 & 72.97 & 21.53 & 10.53 & 51.88 & 54.55 & 41.48 & 46.81 \\
\hline & $\mathrm{C}$ & 65.00 & 81.08 & 12.31 & 0.00 & 54.17 & 89.47 & 42.11 & 40.91 & 45.19 & 51.06 \\
\hline & $\mathrm{D}$ & 0.71 & 0.00 & 0.00 & 0.00 & 4.17 & 0.00 & 0.00 & 0.00 & 0.00 & 0.00 \\
\hline & $\mathrm{E}$ & 0.00 & 0.00 & 0.00 & 0.00 & 0.00 & 0.00 & 0.00 & 0.00 & 0.00 & 0.00 \\
\hline & $F$ & 0.00 & 0.00 & 0.00 & 0.00 & 0.00 & 0.00 & 0.00 & 0.00 & 0.00 & 0.00 \\
\hline \multirow{6}{*}{ Friday } & A & 29.58 & 12.82 & 53.79 & 41.03 & 21.53 & 8.33 & 8.89 & 11.63 & 15.67 & 10.87 \\
\hline & $\mathrm{B}$ & 69.72 & 87.18 & 43.94 & 58.97 & 29.17 & 8.33 & 83.70 & 81.40 & 65.67 & 71.74 \\
\hline & $\mathrm{C}$ & 0.70 & 0.00 & 2.27 & 0.00 & 49.31 & 83.33 & 7.41 & 6.98 & 18.66 & 17.39 \\
\hline & $\mathrm{D}$ & 0.00 & 0.00 & 0.00 & 0.00 & 0.00 & 0.00 & 0.00 & 0.00 & 0.00 & 0.00 \\
\hline & $\mathrm{E}$ & 0.00 & 0.00 & 0.00 & 0.00 & 0.00 & 0.00 & 0.00 & 0.00 & 0.00 & 0.00 \\
\hline & $\mathrm{F}$ & 0.00 & 0.00 & 0.00 & 0.00 & 0.00 & 0.00 & 0.00 & 0.00 & 0.00 & 0.00 \\
\hline
\end{tabular}


Osman, O., J. Codjoe, S. Ishak, J. Rodriguez, and M. Russell

TABLE 8 Change in Level of Service Distribution Results for All Weekdays (Westbound AM Peak) [8:15-8:30] for DCMS Segment

\begin{tabular}{|c|c|c|c|c|c|}
\hline \multirow{3}{*}{ Day } & \multicolumn{5}{|c|}{ LOS Distribution (\%) } \\
\hline & \multirow{2}{*}{$\begin{array}{c}\text { Detector } \\
\text { LOS } \\
\end{array}$} & \multicolumn{2}{|c|}{10001} & \multicolumn{2}{|c|}{10003} \\
\hline & & Before & After & Before & After \\
\hline \multirow{6}{*}{ Monday } & $\mathrm{A}$ & 68.29 & 76.60 & 4.88 & 6.52 \\
\hline & B & 0.00 & 0.00 & 29.27 & 17.39 \\
\hline & $\mathrm{C}$ & 0.00 & 0.00 & 4.88 & 2.17 \\
\hline & $\mathrm{D}$ & 0.00 & 0.00 & 0.00 & 0.00 \\
\hline & $\mathrm{E}$ & 0.00 & 0.00 & 0.00 & 0.00 \\
\hline & $\mathrm{F}$ & 31.71 & 23.40 & 60.98 & 73.91 \\
\hline \multirow{6}{*}{ Tuesday } & $\overline{\mathrm{A}}$ & 79.49 & 53.19 & 0.00 & 0.00 \\
\hline & $\mathrm{B}$ & 0.00 & 0.00 & 15.38 & 8.51 \\
\hline & $\mathrm{C}$ & 0.00 & 0.00 & 0.00 & 0.00 \\
\hline & $\mathrm{D}$ & 0.00 & 0.00 & 0.00 & 0.00 \\
\hline & $\mathrm{E}$ & 0.00 & 0.00 & 0.00 & 0.00 \\
\hline & $\mathrm{F}$ & 20.51 & 46.81 & 84.62 & 91.49 \\
\hline \multirow{6}{*}{ Wednesday } & A & 62.50 & 61.70 & 0.00 & 0.00 \\
\hline & B & 0.00 & 0.00 & 12.50 & 8.70 \\
\hline & $\mathrm{C}$ & 0.00 & 0.00 & 2.50 & 0.00 \\
\hline & $\overline{\mathrm{D}}$ & 0.00 & 0.00 & 0.00 & 0.00 \\
\hline & $\mathrm{E}$ & 0.00 & 0.00 & 0.00 & 0.00 \\
\hline & $\mathrm{F}$ & 37.50 & 38.30 & 85.00 & 91.30 \\
\hline \multirow{6}{*}{ Thursday } & A & 57.50 & 66.67 & 5.00 & 2.17 \\
\hline & $\bar{B}$ & 0.00 & 0.00 & 7.50 & 6.52 \\
\hline & $\overline{\mathrm{C}}$ & 0.00 & 0.00 & 2.50 & 0.00 \\
\hline & $\bar{D}$ & 0.00 & 0.00 & 0.00 & 0.00 \\
\hline & $\mathrm{E}$ & 0.00 & 0.00 & 0.00 & 0.00 \\
\hline & $\mathrm{F}$ & 42.50 & 33.33 & 85.00 & 91.30 \\
\hline \multirow{6}{*}{ Friday } & $\mathrm{A}$ & 95.12 & 89.36 & 4.88 & 6.52 \\
\hline & B & 0.00 & 0.00 & 51.22 & 19.57 \\
\hline & $\mathrm{C}$ & 0.00 & 0.00 & 4.88 & 6.52 \\
\hline & $\mathrm{D}$ & 0.00 & 0.00 & 0.00 & 0.00 \\
\hline & $E$ & 0.00 & 0.00 & 0.00 & 0.00 \\
\hline & $\mathrm{F}$ & 4.88 & 10.64 & 39.02 & 67.39 \\
\hline
\end{tabular}




\section{List of Figure Captions}

FIGURE 1 Study area and locations of ramp meters along the I-12 corridor.

FIGURE 2 Trend of speed prior to implementation of ramp metering on MIST segment.

FIGURE 3 Average speed distribution for 3:15-3:30 PM on Mondays (condition B).

FIGURE 4 Travel time savings for MIST detectors for each weekday and statistical outcome. 


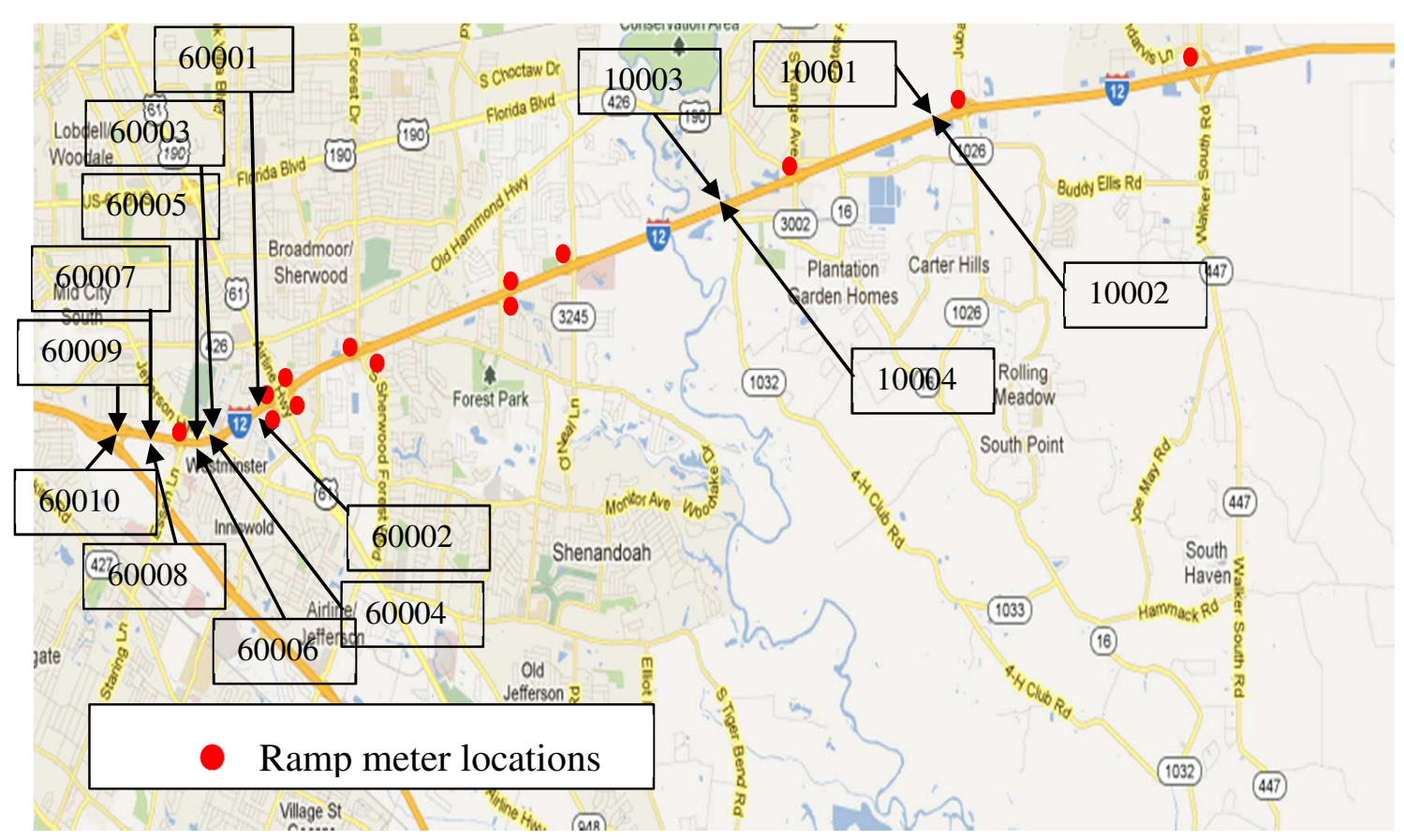

FIGURE 1 Study area and locations of ramp meters along the I-12 corridor. 


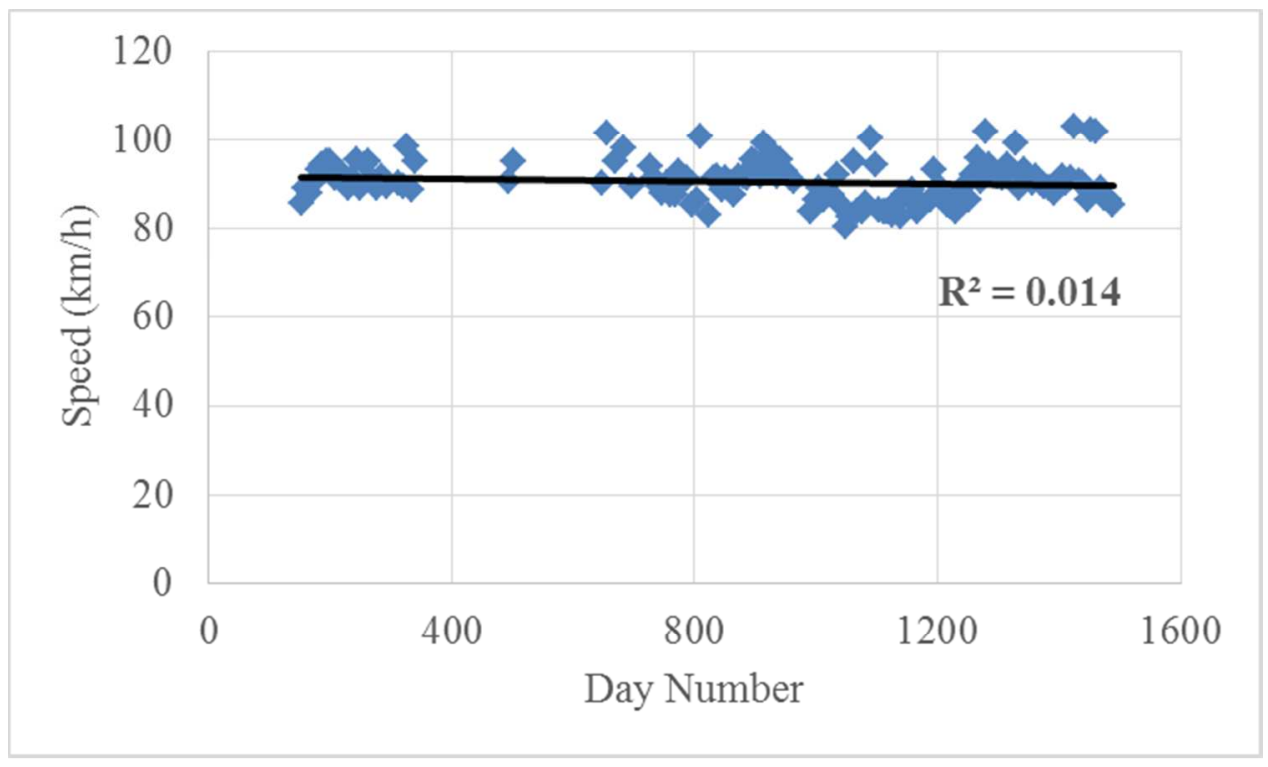

a) 6:30 - 6:45 AM

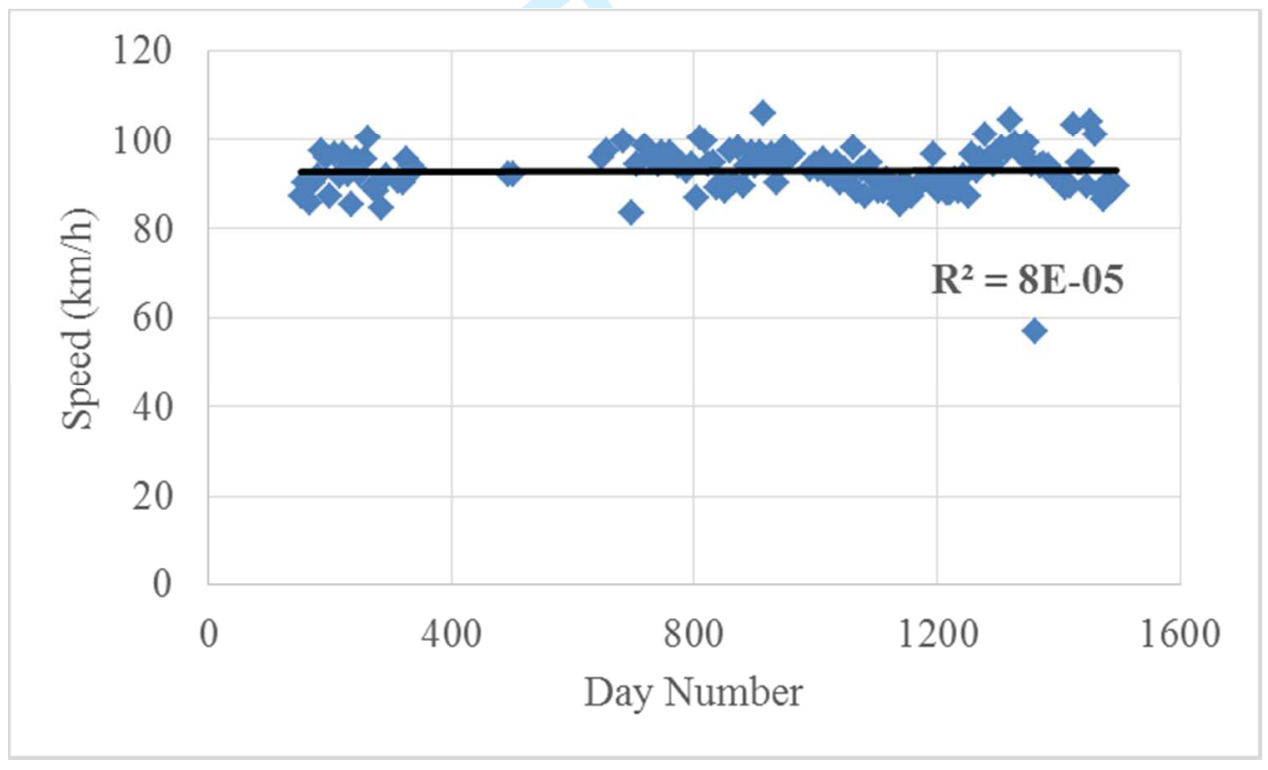

b) 8:45 - 9:00 AM 


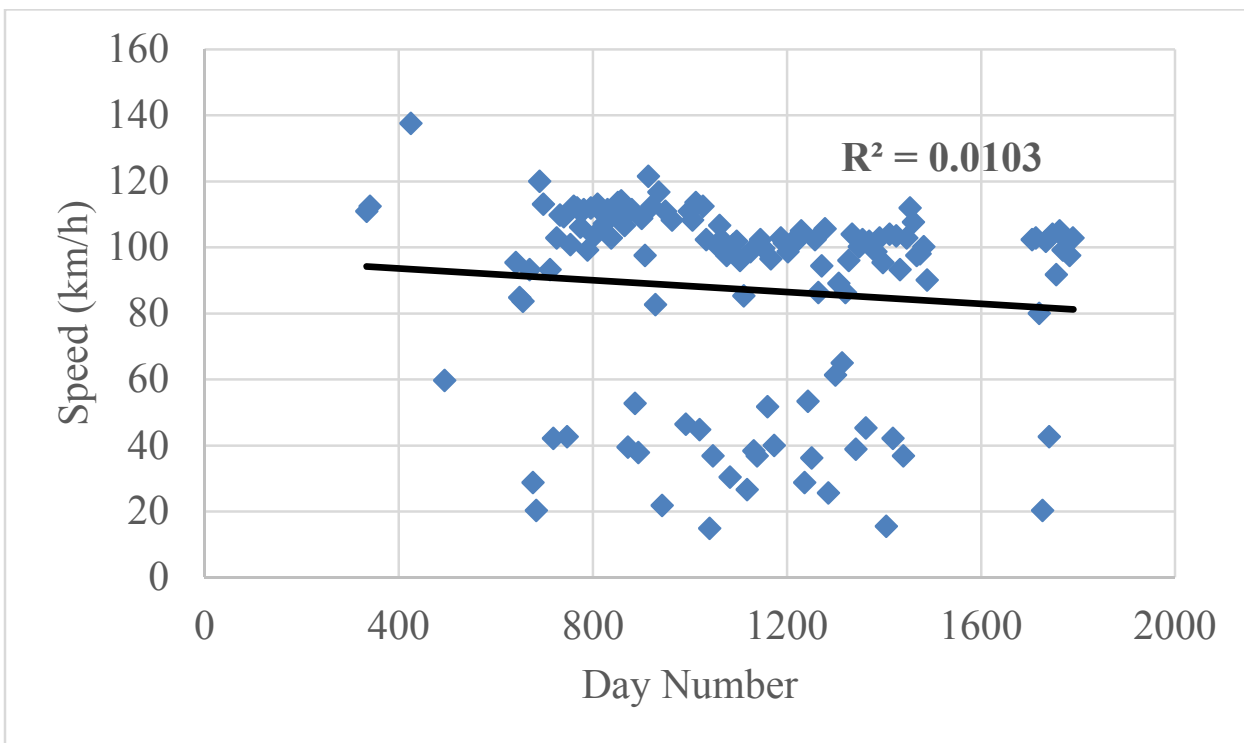

c) 3:30 - 3:45 PM

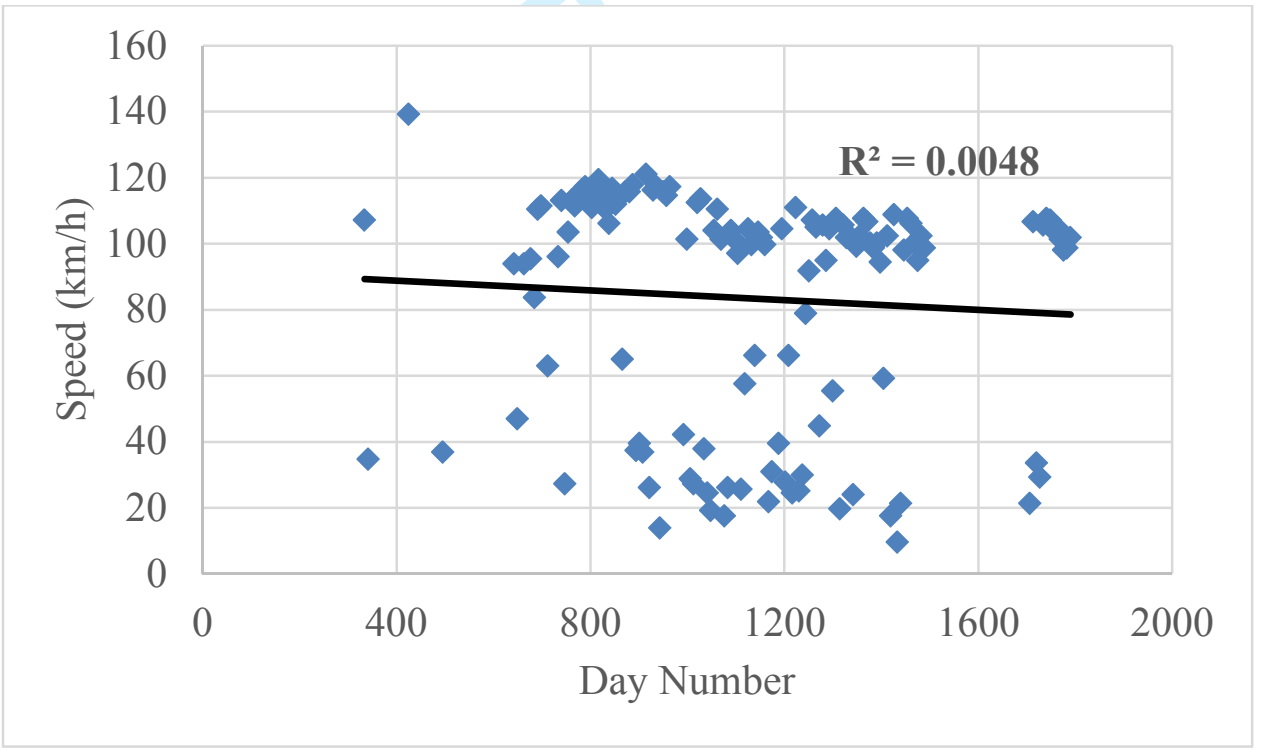

d) 5:45 - 6:00 PM

FIGURE 2 Trend of speed prior to implementation of ramp metering on MIST segment. 


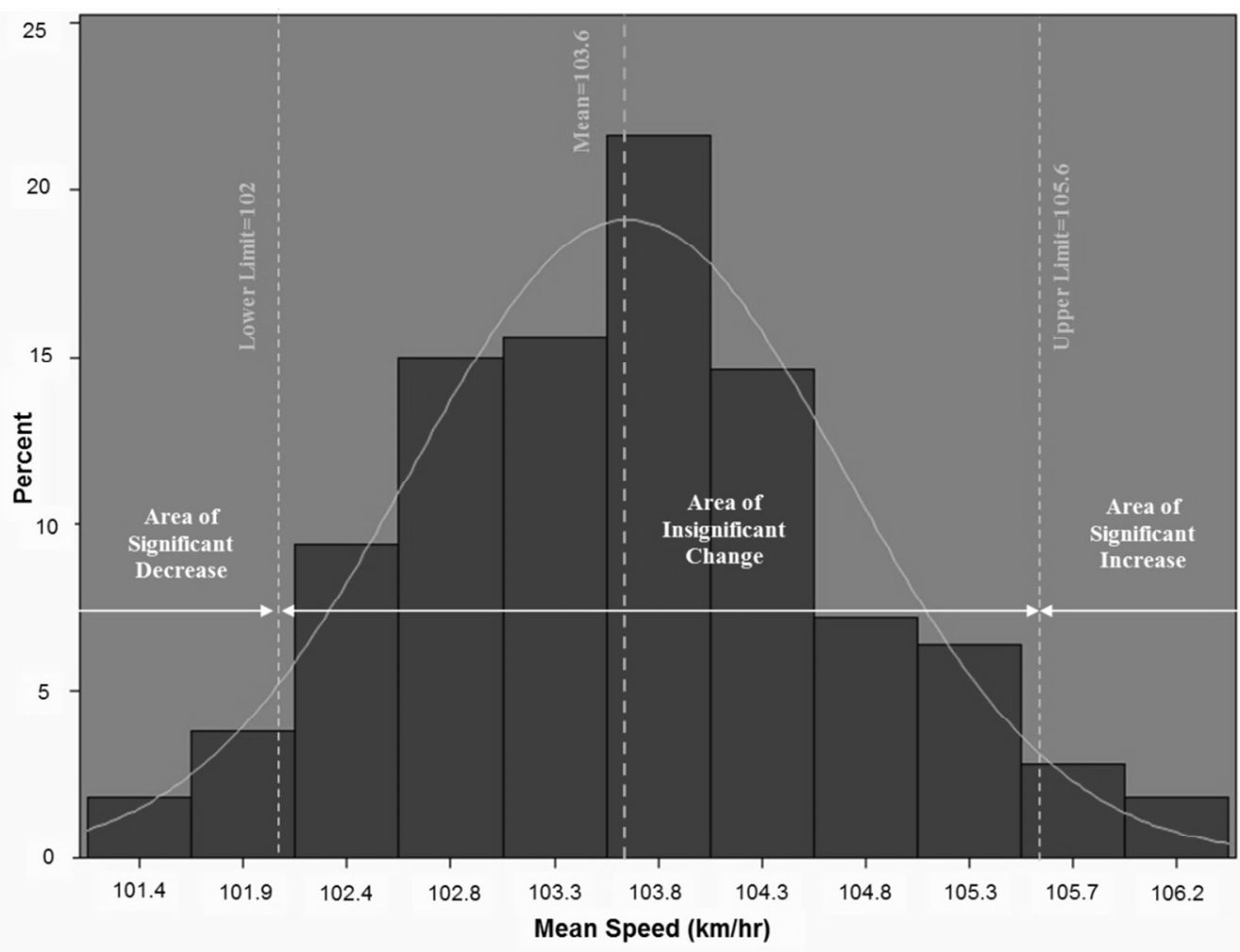

FIGURE 3 Average speed distribution for 3:15-3:30 PM on Mondays (condition B). 


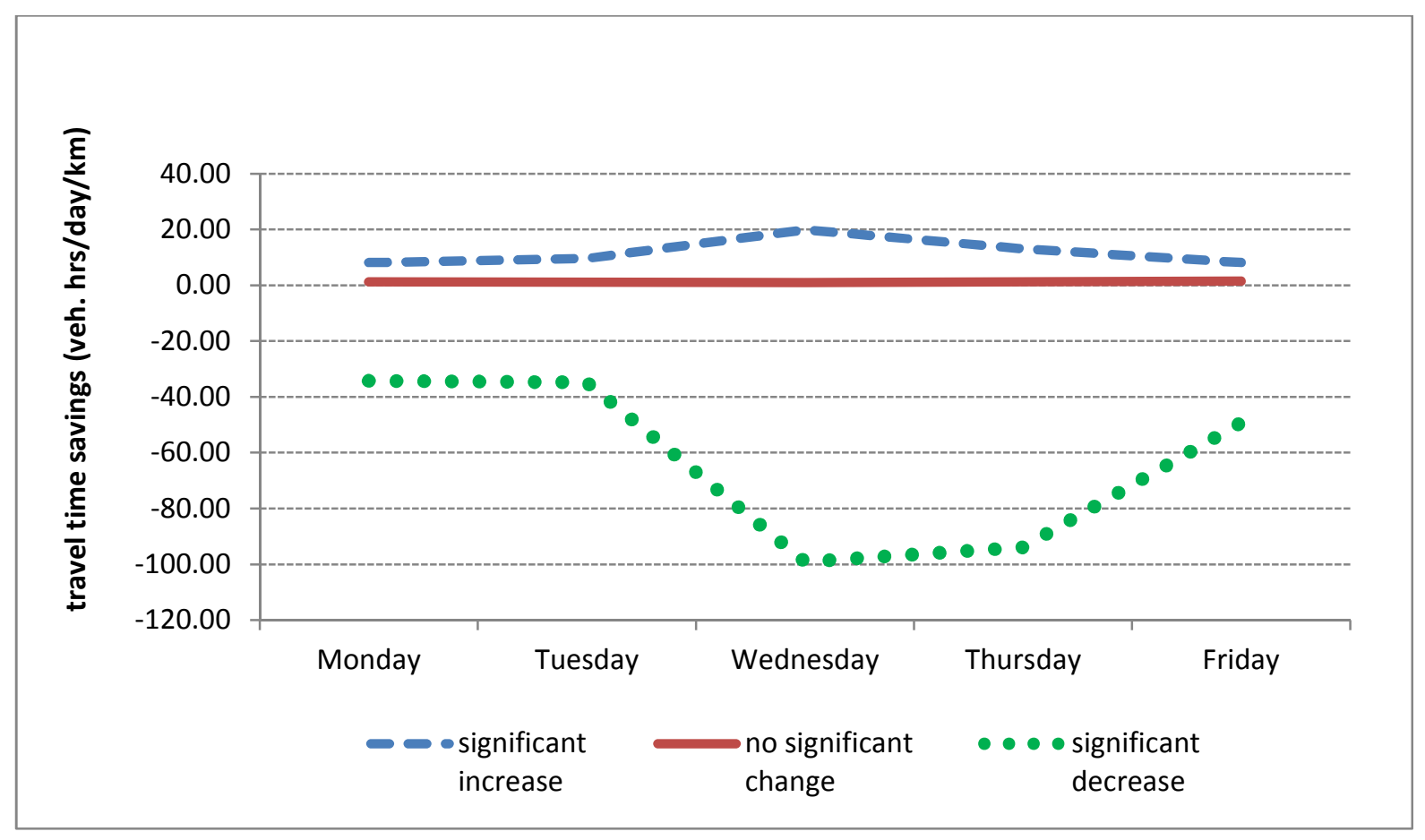

a) Eastbound- PM peak

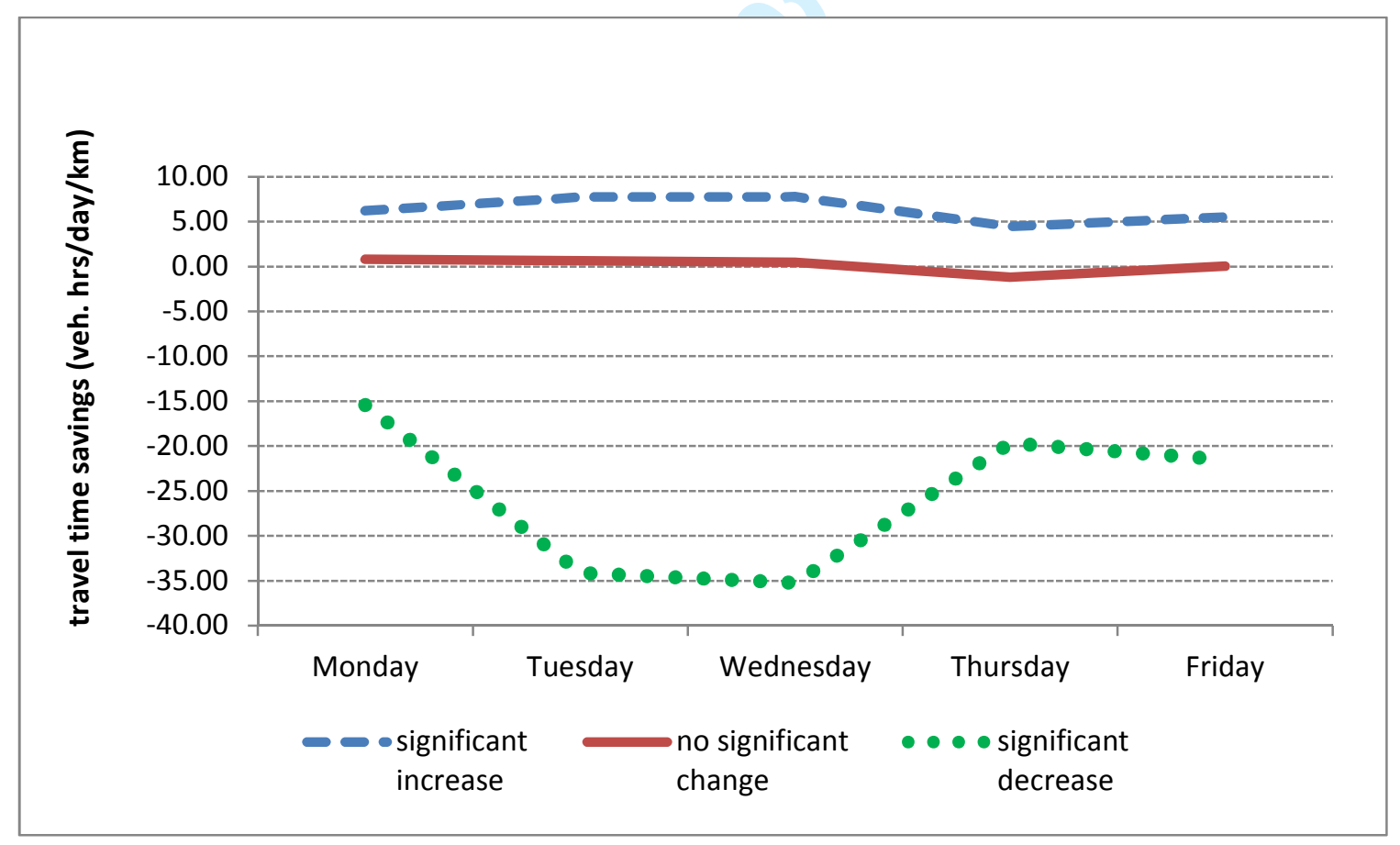

b) Westbound- AM peak

FIGURE 4 Travel time savings for MIST detectors for each weekday and statistical outcome. 